\title{
Analysis of Selected ERP 4.0 Features and Proposal of an ERP 4.0 Maturity Model
}

\author{
Josef Basl $^{1]}$ and Marketa Novakova ${ }^{[1]}$ \\ ${ }^{1}$ Prague University of Economics, W. Churchill Sq. 4, Prague, Czech Republic \\ baslevse.cz, novm29@vse.cz
}

\begin{abstract}
The paper deals with new trends in ERP enterprise information systems that are related to the general trends of Industry 4.0. These trends are covered under the topic of ERP 4.0 in this paper. They are analysed based on a literature review. Selected ERP 4.0 trends are analysed from the point of view of their penetration into the offers of ERP suppliers and the expectations of users in companies. Finally, the main trends identified in ERP 4.0 are reflected in own ERP 4.0 maturity model.
\end{abstract}

Keywords: Enterprise Resource Planning, ERP 4.0, Industry 4.0, maturity model, AI, Internet of Things, IoT, IS/ICT innovation, digital innovation

\section{$1 \quad$ Introduction}

Industry 4.0, with all its attributes, has become a constant concern of suppliers and users of related components and solutions in recent years. However, Industry 4.0 also remains the subject of many research articles. Their focus is gradually changing as knowledge and experience in this area is developed and refined and there is an associated need for further research. In connection with Industry 4.0, not only the focus of research topics is changing, but also the focus of interest of individual authors is changing.

One of the co-authors of this paper is an example of such internal evolution. His publishing activity has gradually reflected interest from general perspectives on Industry 4.0 awareness to business readiness and business ICT vendor readiness in recent years. This article logically results in a focus on ERP 4.0 and its maturity model.

Specifically, these articles were:

a) Analysis of the preparedness of enterprises in industry 4.0, both in the Czech Republic and in comparison with Poland - in 2015/2016 [1], [2]

b) Analysis of the preparedness of companies and their business IS for trends 4.0 in 2015/2016 [3].

c) Analysis of ERP application vendor Industry 4.0 readiness in 2015/2017 [4]

In addition to the state of preparedness of enterprises and their business IS for Industry 
4.0, the author of the article subsequently discussed the models of maturity 4.0 d) Analysis of maturity models 4.0, in particular from the perspective of available models with subsequent formulation of principles applicable to own maturity models, in 2017/2018 [5].

e) Formulation of a metamodel that identified areas, i.e. certain "gaps" where maturity models 4.0 are still missing (one of which was focused on ERP 4.0), also in $2017 / 2018$ [6].

This article focuses specifically on an ERP 4.0 maturity model and is linked to the work above in previous years, especially those dealing with maturity models and identification of potential gaps. Its formulation is based on a pilot analysis of the main 4.0 trends, which can be applied in ERP 4.0.

The following research questions were chosen for this article:

1. What are the main industry 4.0 trends reflected in ERP 4.0 ?

2. What results will the verification of the state of the current supply and demand of trends of ERP 4.0 in the pilot survey on the Czech market?

3. Can these trends be used to specify the ERP 4.0 maturity model?

These three questions are covered in the following sections of this paper. The first question is formulated on the basis of a review by the second co-author of this article.

The second one was also conducted via survey by the second co-author of this article. The third question - the formulation and design was based on a previously conceptually designed maturity model for ERP, based on a general model formulated on the basis of earlier work by the first co-author [6].

\section{$2 \quad$ ERP $4.0-4.0$ trends in ERP applications}

\subsection{ERP 4.0 methodology}

This article focuses primarily on the area identified as ERP 4.0, which is not generally defined, and sometimes other terms are used. Examples of definitions include postmodern ERP [7] or intelligent ERP by SAP. In general, the ERP 4.0 system can be considered as an ERP system that provides the necessary functionality for Industry 4.0. ERP 4.0 is directly based on ERP system functionality, but it takes it to a higher level. ERP 4.0 is strongly supported by Industry 4.0. It must take advantage of all the important 4.0 trends while supporting most of the industry's requirements for industry [8].

Research of available sources was used for analysis of 4.0 trends in applications from articles as well as suppliers and users and more than 30 literary sources were analysed. Criteria (categories) were used by various authors who generally describe the area and typical features for 4.0 trends and Industry 4.0 [7].

These are:

a) trends dominated by the onset of 4.0 - such as cloud computing, IoT integration, blockchain usage, digital twins, edge computing,

b) trends that are dynamically developing in connection with 4.0 - artificial intelligence, business analytics, application mobility, big data, social networks, virtual and augmented reality 


\subsection{Results - main ERP 4.0 features}

To evaluate the results of the ERP 4.0 trend analysis, an analysis of the frequency of occurrence of individual trends was used. According to the resulting frequency, the following trends can be classified as the most recent trends in ERP systems [7]:

- Cloud computing used in ERP systems is the most frequently reported trend [8],[9], [10], [11], [12]. Cloud ERP is mentioned as a gateway to modernization, mainly because of lack of innovations available in older traditional solutions

- Internet of Things (IoT) is a term meaning the connection individual physical devices via the Internet without the active involvement of a person. IoT technology can improve accuracy and expand data availability, resulting in intelligent and more flexible ERP systems [13]. By combining ERP with attached devices (IoT), businesses can use real-time data from any device in the world to gain a competitive advantage [14], [15],[16].

- Artificial intelligence and machine learning are among the most frequently mentioned trends. They have already rocked many areas of business, but when it comes to key business functions, the use of artificial intelligence is still in the early stages. Artificial intelligence ERP solutions can take on routine tasks performed so far by humans, design more efficient work processes, or communicate with customers. This could reduce operating costs and increase efficiency.

With lesser frequency, the following digital twin trends emerged in the survey, promising to provide better responses to change, help extend asset life and optimize performance. And also the trend of implementing blockchain technology into ERP systems. It turns out that the most common application of blockchain is to use it as an online book of account records that stores transactions made by users. Combined with cryptography, it can ensure anonymity of operations and prevent unauthorized transactions. The use of Blockchain in ERP promises to change industry by enabling confidence, providing transparency and reducing friction between business ecosystems, potentially reducing costs, reducing transaction clearing time and improving cash flow [8].

Other identified trends include Big Data and their interconnection with ERP and the combination of ERP solutions with Business Intelligence tools. The use of In-Memory Computing (IMC) in ERP is gradually expanding. IMC enables the user to process massive amounts of data at a rate faster and with significantly shorter latency in access to information.. Last but not least, mobile ERP applications were often mentioned in the survey. Mobile ERP applications can help companies to improve service quality, improve business relationships, increase employee productivity, and make communication with customers easier and faster [17]. In recent years, social ERP, a system that includes traditional ERP functionality but has integrated social media tools, has been a 
trendsetter. These tools are built into the system in such a way that both internal employees and external suppliers, customers or other partners can work together.

It is expected that in the future it will be possible to communicate with the ERP system using voice commands. This will again speed up, because a person can say up to 150 words in a minute, but can write only 40 . In addition, voice interaction is more natural, efficient and convenient for a person. So there is no reason not to communicate with the ERP system in this way with the help of simple queries, for example, to find the number of sales in the database for the last quarter.

\section{Analysis of supply/demand view on the most important attributes of ERP 4}

\subsection{Methodology of data collection}

The analysis was carried out on the basis of findings from the search part in the form of a questionnaire [7]. The questions were focused mainly on the main trends mentioned by other authors:

cloud [18]

internet of Things (IoT) [19], and

artificial intelligence [20].

In total, the questionnaire contained 17 questions and the Google Forms cloud service was used to create it. The questions concerned the offer of each trend by its supplier in full or partial range at present, or its planned delivery in the 2 or 5 years horizon. These questions were supplemented by questions determining their overall familiarity with the topic on the one hand and the question of whether customers are interested in the questioned 4.0 trends in connection with ERP.

Respondents were selected from the professional portal SystemOnLine.cz from the overview of ERP systems. The collection of replies was closed on 31 March 2019. The response to the survey was $30.2 \%$. A total of 86 ERP system suppliers were addressed, of which 26 companies replied to the questionnaire.

\subsection{Results from analysis}

\section{ERP and cloud}

The first set of questions related to the cloud ERP trend. All ERP vendors surveyed said they were familiar with the trend (23\% said they had a general idea and $79 \%$ of respondents were well versed in this issue).

Answers from 26 companies suggest that $65.4 \%$ of ERPs are cloud-based (30.8\% of 
enterprises offer cloud ERP in SaaS, and 34.6\% offer cloud ERP solutions in another model). While $75 \%$ of companies offer a full ERP functionality in a cloud solution, $6.3 \%$ offer hybrid ERP systems where only certain functions are transferred to the cloud, and $18.8 \%$ offer both solution options.

The remaining 34.6\% do not currently offer any cloud ERP solutions. Of these, $22.2 \%$ plan to offer a cloud ERP system within 2 years and $33.3 \%$ are considering deploying within 5 years. Roughly half $(44.4 \%)$ of those who do not offer ERP in the cloud today do not plan to do so in the future.

Investigating this trend showed that companies evaluate customer interest in it on a scale of 1 to 5 (from min to max) fairly evenly and indefinitely at a certain value, with an average value of interest of 2.5 .

\section{ERP and IoT (Internet of Things)}

. The second group of questions concerned the use of the Internet of Things in ERP systems. The term Internet of Things itself has never been encountered by $3.8 \%$ of companies, $3.8 \%$ are aware of this issue, but do not know exactly what it means, $46.2 \%$ have a general idea and the same $46.2 \%$ well orientated. It can be seen that this trend is somewhat less known to businesses than the previous cloud ERP trend.

A $26.9 \%$ of companies are actively extending their ERP system using IoT technologies, $23.1 \%$ of companies plan to expand the ERP system using the Internet of Things within 2 years and $15.4 \%$ plan to do so within 5 years. The remaining one third $(34.6 \%)$ of companies do not use IoT in their ERP solutions, nor do they plan to use it in the future.

If the company stated that it is actively extending its ERP system through the Internet of Things, a supplementary question followed on the functional areas in which the Internet of Things is applied. There were multiple answers to this question and there was also the possibility to add your own answer. Most respondents said they used the Internet of Things to track inventory levels, half of IoT companies used predictive maintenance, a third of respondents reported location and shipment tracking, and one company used IoT to plan production.

At the same time, the company assesses the interest of companies in this trend as low (average value of 1.8 ) and roughly one half rated them as 1 , i.e. as little to no interest.

\section{ERP and Artificial Intelligence}

The third group of questions was focused on the use of artificial intelligence in ERP systems. Most companies are familiar with this term (53.8\% of companies say they are well versed in this issue and $42.3 \%$ of enterprises have a general idea of artificial intelligence). Only $3.8 \%$ of companies have never encountered this term. In terms of using $\mathrm{AI}$ in ERP, none of the companies indicated that artificial intelligence 
was at the core of their ERP solution. However, about a quarter (23.1\%) said they are actively expanding their ERP system with artificial intelligence. The same percentage (23.1\%) of companies plan to extend the ERP system using AI within 2 years and $19.2 \%$ within 5 years. Around a third of businesses reported that their ERP system does not use artificial intelligence, nor do they plan to do so.

For companies that said they were actively expanding their ERP system through artificial intelligence, most respondents said they used artificial intelligence in predictive inventory management, two-thirds used it in data analysis and processing, and decision support. One third of AI businesses use conversational systems and digital assistants. Only one company has introduced artificial intelligence in predictive maintenance. Customer interest in ERP solutions using AI is similar to the IoT trend. The average result is just above 2 and so far, customers have not been interested in this trend. To summarize the main findings of the analysis, it should also be remembered that ERP systems were not evaluated qualitatively, as it was important from the point of view of research methodology whether the trend was even offered. The survey results therefore do not reflect the quality of the provider's offer, but only its relation to selected ERP trends.

According to the results of the questionnaire, we can generally say that awareness of given trends among providers is quite good, only some companies have not heard about the Internet of Things and Artificial Intelligence.

It was again confirmed that the world of ERP is quite conservative and quite resistant to change. The cause is not primarily on the suppliers' side, but primarily on the ERP users' side. Customers are often not interested in new trends and technologies, which is mainly due to the low willingness to change their habits and knowledge. In the case of Czech providers, it is also necessary to realize that they are targeted primarily at small and medium-sized enterprises. They do not have as high functional requirements for ERP systems as multinational companies. In addition, they may be discouraged by large initial costs, for example in the case of the introduction of the Internet of Things and artificial intelligence.

\section{$4 \quad$ ERP 4.0 Maturity model}

\subsection{Methodology of maturity model}

The research findings and analyses described above were reflected in the refinement of the ERP 4.0 maturity model. In fact, the key trends of 4.0 can be described from the ERP perspective as 4.0 key enablers. It will enable ERP applications to provide improved and expanded capabilities in traditional functionality of ERP (in the original meaning of ERP - Enterprise Resources Planning):

a) Improved enterprise resource planning - which will be able to leverage data from IoT sensors, apply the potential of machine learning and artificial intelligence to handle 
job fulfilment needs more quickly and with more available data, including integration and planning requirements from predictive maintenance. Also interesting is the idea of abandoning the central, centrally conceived role of a plan in ERP, which opens the way to decentralization and autonomy of enterprise planning.

b) Better decision support - which also builds on decision-making based on more data (thanks to IoT), digital twin data and much data from outside enterprise sources and non-business databases, has already been outlined by the Competitive Intelligence (CI) trend in the previous decade; the integration of social networks and the increasing digital footprint.

c) Better information sharing - thanks to the "tracing" of orders, generally goods, throughout the logistics chain, but also to the "tracing" of the customer and their requirements and needs with a high share of mobile applications

d) Higher automation and robotization of all processes, i.e. by supporting administrative processes and not only production and transport robots and automation.

These functional trends of ERP will be reflected in the key model dimensions, i.e. the columns of the proposed maturity model (see Table 1). Its overall concept is based on the previous work and studies of the first co-author [6]. They are based on an analysis of 27 different maturity models, formulating the concept of the model and approach to determine dimensions (columns) and degrees of maturity (rows).

Maturity is evaluated on a 6-degree scale from 0 to 5 , where 5 is the highest value and represents the highest possible degree at a given time under given technological, economic, environmental, social, political, legal, health and other important conditions. Lower steps then mean partial fulfilment of the highest possible degree and then the way to it.

\subsection{Proposal of ERP 4.0 maturity model}

In accordance with the ERP 4.0 maturity model described above and exploration of the analysis of ERP 4.0 trends, the following dimensions have been proposed for the ERP 4.0 maturity model:

- The overall model of providing ERP services aiming at cloud

- Integrated technology trends 4.0 aiming at IoT, digital twin, blockchain, etc.

- Improved core functionality of ERP like planning and decision support

- Increasing levels of automation and robotization of business processes supported by ERP. 


\begin{tabular}{|c|c|c|c|c|}
\hline & $\begin{array}{l}\text { Business Model - } \\
\text { on promise/cloud }\end{array}$ & $\begin{array}{l}\text { Technology - } \\
4.0 \text { trends }\end{array}$ & $\begin{array}{l}\text { Data - } \\
\text { planning and decision } \\
\text { support }\end{array}$ & $\begin{array}{l}\text { Processes- } \\
\text { digitization and } \\
\text { automation }\end{array}$ \\
\hline$\overline{0}$ & Own solution & $\begin{array}{l}\text { Based on relational } \\
\text { database }\end{array}$ & Data integration within ERP & $\begin{array}{l}\text { Basic ERP processes } \\
\text { automated }\end{array}$ \\
\hline 1 & $\begin{array}{l}\text { Partly own, partly on } \\
\text { promise }\end{array}$ & $\begin{array}{l}\text { Internet connection, } \\
\text { mobility of solutions }\end{array}$ & $\begin{array}{l}\text { Data integration with other } \\
\text { application }\end{array}$ & $\begin{array}{l}\text { Some new processes } \\
\text { digitized and automated }\end{array}$ \\
\hline 2 & Complex on promise & In memory computing & Data analysis & $\begin{array}{l}\text { Some new } 4.0 \text { processes } \\
\text { digitized and automated }\end{array}$ \\
\hline 3 & $\begin{array}{l}\text { On promise, partly } \\
\text { cloud }\end{array}$ & $\begin{array}{l}\text { Social integration, mobile } \\
\text { solutions }\end{array}$ & Business Intelligence (BI) & $\begin{array}{l}\text { Selected new } 4.0 \text { processes } \\
\text { digitized and automated }\end{array}$ \\
\hline 4 & Complex as a service & loT, digital twin & Competitive Intelligence & $\begin{array}{l}\text { All key } 4.0 \text { processes full } \\
\text { automated }\end{array}$ \\
\hline 5 & $\begin{array}{l}\text { Complexcloud } \\
\text { solution }\end{array}$ & $\begin{array}{l}\text { Blockchain, edge computing. } \\
\text { quantum computing }\end{array}$ & $\begin{array}{l}\text { Artificial Intelligence (AI) } \\
\text { RPA }\end{array}$ & $\begin{array}{l}\text { All business processes full } \\
\text { automated }\end{array}$ \\
\hline
\end{tabular}

Table 1. Picture 4: ERP 4.0 maturity model

The model design includes the key factors monitored by the analysis - i.e. cloud ERP, IoT and artificial intelligence. In terms of their importance today, they are placed in the highest stages of maturity in the model. The technology dimension is complemented at the highest level by trends like blockchain and edge computing.

The use of the proposed maturity model ERP 4.0 is not only in the as-is state mapping, but also in the to-be state formulation and the overall trajectory of digital transformation and innovation in the enterprise.

\section{Conclusion}

The analysis helped to formulate the maturity model content for ERP 4.0 applications. This article is based on the assumption that an ERP 4.0 system can be considered as an ERP system that provides the necessary functionality for Industry 4.0. ERP 4.0 is also based on the ERP system's functionalities, but it has moved up to a higher level thanks to the applications of 4.0 trends. The main identified 4.0 trends from the literature review were also verified in the survey among ERP suppliers in the Czech Republic. 


\section{References}

1. Basl, J.. Pilot Study of Readiness of Czech Companies to Implement the Principles of Industry 4.0. Management and Production Engineering Review [online]. 2017, 8, nr. 2, pp. $3-$ 8. ISSN 2080-8208. DOI: 10.1515/mper-2017-0012.

2. Basl, J., Sasiadek, M.. Comparison of Industry 4.0 Application Rate in Selected Polish and Czech Companies. In: IDIMT-2017 Digitalization in Management, Society and Economy [online]. Poděbrady, 06.09.2017 - 08.09.2017. Linz : Trauner Verlag Universität, 2017, s. 401-410. ISBN 978-3-99062-119-6.Available: http://idimt.org/wp-content/uploads/proceedings/IDIMT_proceedings_2017.pdf

3. Basl, J., Kopp, J.. Study of the Readiness of Czech Companies to the Industry 4.0. Journal of Systems Integration [online]. 2017, 8, nr 3, pp. 40-45. ISSN 1804-2724. DOI: 10.20470/jsi.v8i3.313.

4. Basl, J.. Penetration of Industry 4.0 Principles into ERP Vendors' Products and Services A Central European Study. In: Research and Practical Issues of Enterprise Information Systems [online]. Shanghai, 18.10.2017-20.10.2017. Cham : Springer, 2018, pp. 81-90. ISBN 978-3-319-94844-7. eISBN 978-3-319-94845-4. DOI: 10.1007/978-3-319-94845-4_8.

5. Basl, J.. Analysis of Industry 4.0 Readiness Indexes and Maturity Models and Proposal of the Dimension for Enterprise Information Systems. In: Research and Practical Issues of Enterprise Information Systems [online]. Poznan, 18.09.2018 - 19.09.2018. Cham : Springer, 2018, pp. 57-68. ISBN 978-3-319-99039-2. eISBN 978-3-319-99040-8. DOI:

6. Basl, J., Doucek, P. Metamodel of Indexes and Maturity Models for Industry 4.0 Readiness in Enterprises. In: IDIMT-2018 Strategic Modeling in Management, Economy and Society [online]. Kutna Hora, 05.09.2018 - 07.09.2018. Linz : Trauner Verlag Universität, 2018, pp. 33-40. ISBN 978-3-99062-339-8. Available: https://idimt.org/wp-content/uploads/proceedings/IDIMT_proceedings_2018.pdf

7. Novakova, $\vec{M} .:$ Trends of enterprise information systems in 4.0 conditions, Diploma Thesis, University of Economics, Prague, 2019

8. Gartner, Inc., 2018. Gartner Identifies the Top 10 Strategic Technology Trends for 2019. Gartner.com [online] [vid. 2019-02-24]. Available z: https://www.gartner.com/en/newsroom/press-releases/2018-10-15-gartner-identifies-the-top-10-strategic-technology-trendsfor-2019

9. Srubar, J.: QAD System and its support by Industry 4.0, Diploma Thesis, University of Economics, Prague, 2019

10. Accenture, 2018. 2019 ERP Trends [online] [vid. 2019-02-25]. Available: https://www.accenture.com/t00010101T000000Z_w_/gb-en/_acnmedia/PDF-90/AccentureUnleashing-Exponential-Evolution-PDF.pdf

11. Philips, Ch., 2018. Here Are the Biggest Cloud ERP Trends of 2018. Charles Phillips [online]. [vid. 2019-02-25]. Available: https://charlesphillips.me/here-are-the-biggestcloud-erp-trends-of-2018

12. Rust, O., Martinez, 2018. 5 Enterprise Resource Planning (ERP) Trends to Watch in 2019| PCMag.com [online] [vid. 2019-02-25]. Available: https://www.pcmag.com/article/351807/5-enterprise-resource-planning-erp-trends-to-watch-in-201

13. Stark Ch. , 2012. The History of Cloud Computing. Cetrom Information Technology, Inc. [online] [vid. 2019-03-10]. Available: https://www.cetrom.net/uncategorized/the-historyof-cloud-computing

14. Quirk, E., 2018. The Latest Trends in Enterprise Resource Planning [online] [vid. 2019-0225]. Available: https://solutionsreview.com/enterprise-resource-planning/erp-trends-2018/ 
15. Macola Software, 2018. 8 ERP Trends for 2018 [online] [vid. 2019-02-26]. Available: https://macola.com/images/pdf/8-erp-trends-macola.pdf?utm_source=macola_com\&utm_medium $=$ pdf\&utm_campaign $=8$ _erp_trends\&utm_term $=$ click

16. I-SCOOP, 2018. Artificial intelligence in business: challenges and recommendations. iSCOOP [online] [vid. 2019-03-28]. Available: https://www.i-scoop.eu/artificial-intellig ence-cognitive-computing/artificial-intelligence-business-ai-4-business-summit-belgium

17. Lee, In a Kyoochun L, 2015. The Internet of Things (IoT): Applications, investments, and challenges for enterprises. Business Horizons [online]. 58(4), 431-440. ISSN 0007-6813. Available: doi:10.1016/j.bushor.2015.03.008

18. Xu X.: From cloud computing to cloud manufacturing, Robotics and Computer-Integrated Manufacturing, vol. 28, no. 1, pp. 75-86, 2012

19. Wang S., Wan J., LI D., Zhang C.: Implementing Smart Factory of Industrie 4.0: An Outlook, International Journal of Distributed Sensor Networks, Volume 2016 (2016), Article ID 3159805, 10 pages, http://dx.doi.org/10.1155/2016/3159805

20. Ale, Zach, 2018. How AI Is Shaping the Future of ERP Software. Software Advice [online] [vid. 2019-03-28]. Available: https://www.softwareadvice.com/resources/ai-erp 